\title{
Colonic irritability due to a mercurial bacteriostat in retention enemata
}

\author{
S. G. FLAVELL MATTS, J. H. BARON, ${ }^{1}$ A. M. CONNELL, ${ }^{2}$ \\ AND J. E. LENNARD-JONES ${ }^{3}$ \\ From the Royal Hospital, Wolverhampton, and the Research Department, \\ St. Mark's Hospital, London
}

SYNOPSIS These observations show that thiomersal, used as a bacteriostatic agent for retention enema solutions, irritates the colon. Investigations leading to the choice of a non-irritant bacteriostatic agent are described. The presence or concentration of sodium chloride in the solution does not seem to be important.

During his pioneer studies on the use of topical hydrocortisone therapy in ulcerative colitis, Truelove (1956) used hydrocortisone as the free alcohol dissolved in physiological saline containing $4.5 \%$ ethyl alcohol. He found that the histological appearance of rectal mucosal biopsy specimens did not improve after treatment even though there was often symptomatic and sigmoidoscopic improvement. When hydrocortisone hemisuccinate sodium became available, which is freely soluble in water alone, he noted (Truelove, 1957) that clinical and histological improvement now occurred together. He suggested that the dilute alcohol used initially might possibly have prevented healing of the mucosa.

One of us (Matts, 1960) introduced a method of treatment for ulcerative colitis using a solution of prednisolone-21-phosphate given from a disposable enema bag. The enema was freshly prepared by the patient, using a solution tablet dissolved in a vehicle containing a para hydroxy benzoate ester as a fungistat and bacteriostat. To make the treatment simpler it seemed advantageous to have a readyprepared solution of prednisolone-21-phosphate. When such a ready-prepared solution is prepacked in a disposable plastic enema bag it is necessary to include a more effective bacteriostat in the formula, and thiomersal 1 in 10,000 was chosen because it is an accepted ingredient at this concentration in preparations such as eye drops.

'Late Leverhulme research scholar, Institute of Clinical Research, Middlesex Hospital Medical School, London.

${ }^{2}$ Member, M.R.C. Unit for Research in Gastroenterology, Central Middlesex Hospital, London.

${ }^{3}$ Late member, M.R.C. Department of Clinical Research, University College Hospital Medical School, London.

\section{THE PRESENT INVESTIGATION}

A double blind controlled trial of the ready-prepared enema solution of prednisolone-21-phosphate containing thiomersal as bacteriostat was started at St. Mark's Hospital in out-patients with active leftsided ulcerative colitis. The patients were divided randomly into two groups, one being given enema bags containing $20 \mathrm{mg}$. of prednisolone (as the 21 phosphate) in $100 \mathrm{ml}$. of water with thiomersal 1 in 10,000 as the bacteriostat, the other group receiving the same volume of solution with the bacteriostat but no prednisolone. Treatment was given every night for two weeks and the results were then assessed. If there had been no improvement during these two weeks the alternative enema pack was prescribed. Any apparently beneficial treatment was given for a total of four weeks.

Twenty-one patients were admitted to the trial. Two patients were subsequently excluded, one because she was found by barium enema to have extensive ulcerative colitis, and the other because she required hospital admission for treatment of a mesenteric embolus which did not appear to be related to the treatment. The final assessment of all the treatments is shown in the following table:-

\begin{tabular}{lccc} 
& Kemission & Improved & $\begin{array}{c}\text { No Benefit } \\
\text { or Worse }\end{array}$ \\
\hline $\begin{array}{l}\text { Control } \\
\text { Active }\end{array}$ & 4 & 1 & 9 \\
& 4 & 2 & 8
\end{tabular}

Only four patients were able to retain the enemas all night, 13 retained the enemas for four hours or 
less, and two patients were unable to retain the enemas at all. Five patients given the active treatment and one given the control treatment complained of abdominal pain after the enemas and it seemed that the pain occurred or became worse after several enemas had been given.

The results show that the treatment did not benefit the patients. In view of this failure and of the complaints of pain by some of the patients, it occurred to us that the bacteriostat might be irritant. For this reason observations were made by three normal volunteers who gave themselves on three nights retention enemas made up as follows:- Water 100 $\mathrm{ml}$., water $100 \mathrm{ml}$. + para hydroxy benzoate esters, modified combination as now used (Matts, 1961), and water $100 \mathrm{ml}$. + thiomersal 1 in 10,000 .

The order of administration was arranged in a latin square pattern and two of the subjects did not know what the enema bags contained. None of the subjects experienced any side-effects from the water or the water plus hydroxy benzoate esters but all experienced diarrhoea and colic with the solution of thiomersal. One of the subjects gave himself an enema of $100 \mathrm{ml}$. water plus para hydroxy benzoate esters for 12 successive nights without experiencing any unpleasant symptoms.

About the same time as these studies were in progress, one of us (S.G.F.M.) independently gained the impression that thiomersal was irritant when tried in two patients. He therefore abandoned its use in treatment but investigated the matter further. Four patients in whom colitis was in remission and whose rectal mucosa appeared normal were given on one occasion a $100 \mathrm{ml}$. retention enema containing thiomersal and on another occasion one containing para hydroxy benzoate esters. Inspection of the rectal mucosa 30 minutes after administration of the thiomersal preparation revealed reddening and mucosal oedema, whereas 30 minutes after the para hydroxy benzoate esters preparation the rectal mucosa still appeared normal. When given thiomersal all the patients experienced rectal discomfort and three out of four found difficulty in retaining the enema; they experienced no symptoms after para hydroxy benzoate esters.

In similar studies, $100 \mathrm{ml}$. retention enemas of tap water, $0.45 \%$ saline, physiological saline, and $1.8 \%$ saline were each given to five patients in whom colitis was in clinical remission and in whom the rectal mucosa looked normal. In none of the 20 patients was there any change in the sigmoidoscopic appearance nor did they experience any discomfort.

\section{CONCLUSION}

The finding that thiomersal, 1 in 10,000 , is irritant to the human colon was unexpected but it does emphasize the need for carrying out investigations on the influence of the ancillary as well as the active ingredients of enema solutions. As a result of these investigations a satisfactory pre-packed solution of prednisolone phosphate for rectal use was achieved (Matts, 1961).

We thank Miss E. Allen, B. Pharm., for help in arranging the controlled trial.

\section{REFERENCES}

Matts, S. G. F. (1960). Local treatment of ulcerative colitis with prednisolone-21-phosphate enemata. Lancet, 1, 517-519. (1961). Intrarectal treatment of 100 cases of ulcerative colitis with prednisolone-21-phosphate enemata. Brit. med. J., 1, 165-168.

Truelove, S. C. (1956). Treatment of ulcerative colitis with local hydrocortisone. Ibid, 2, 1267-1272.

- (1957). Treatment of ulcerative colitis with local hydrocortisone hemisuccinate sodium. Ibid, 1, 1437-1443. 